\section{Universities, the military, and the means of destruction in the United Kingdom}

Chris Langley

$\mathrm{T}$

he United Kingdom and the United States both allocate significant proportions of their military budgets to procurement of sophisticated technological weapons and support infrastructure as well as maintaining a sustained high-technology research and development (R\&D) effort. ${ }^{1}$ In the United Kingdom, government spending on military R\&D - currently about $£ 2.7$ billion - represents around 32 percent of total government R\&D allocations. ${ }^{2}$ This overshadows the R\&D spending of the arms companies, as even the most R\&D-intensive military companies like BAE Systems and Rolls Royce spend quite modest sums on R\&D ( $£ 1.1$ billion and $£ 282$ million, respectively, in 2005). ${ }^{3}$

In addition, there has been a marked growth in military funding going to universities. An estimate obtained from the Ministry of Defence (MoD) under the Freedom of Information Act indicates that about $£ 22$ million of the Ministry’s Science and Technology Program funding went to U.K. universities in fiscal year 2005/6. To this must be added support for university R\&D for military objectives provided by the former Department for Trade and Industry (DTI) and funding provided by defense and aerospace corporations. These numbers suggest that university-related military R\&D is substantial. And when combined with wider changes to make universities increasingly commercialized or entrepreneurial, their growing links with the military have influenced the role of universities in society and appear to be forming a nexus, linking them with arms companies and government departments which maintain military R\&D effort. ${ }^{4}$ Thus, counter-intuitively, since the end of the Cold War universities have come to play an increasing role in supplying $R \& D$ expertise for military purposes, a trend that has attracted little comment or analysis. ${ }^{5}$

This article examines the military R\&D nexus in the United Kingdom, considers what maintains it, and how it drives a high-technology weapons-based approach to security. It describes some of the commercializing pressures that universities have faced in the last twenty years and the implications this has for framing security.

Science and military ambitions

Wide-ranging military-related research is relatively new within universities in the United Kingdom. Edgerton argues that U.K. universities were certainly not centers of wartime research and development in the 1930s. ${ }^{6}$ And Freeman and Soete describe how the Second World War and the Korean War played an important role in laying the ground for government investment in military $\mathrm{R} \& \mathrm{D}$, a trend strengthened during the Cold War period. This generated justifications for a huge growth in public spending on $\mathrm{R} \& \mathrm{D}$ and the active involvement of universities in Britain and the United States. It also institutionalized science and technology policy in military affairs. $^{?}$

Up until the late 1990 s U.K.

defense research was largely carried out by the Defence Evaluation Research Agency (DERA, which in July 2001 split into the Defence Science and Technology Laboratory, DSTL, and QinetiQ), while much development work was nonetheless placed with industry. In 1994-95 around two percent of gross defense R\&D spending was contracted to R\&D in universities, ${ }^{8}$ and one-third was spent in the Ministry of Defence's (MoD) own research establishments. But since then things have changed considerably, with the research income of many universities including significant sums from the military sector. For instance, Cambridge University in 2005 received 11 percent of its U.K.-origin industrial research funding from the aerospace and military sector, and a further 15 percent of its overseas-origin research funding came from military sources such as Boeing and the U.S. Army and Navy. Imperial College London received funding in 2003 to 2006 from military corporations like General Dynamics, Thales, QinetiQ, and EADS, with General Dynamics providing the largest amount $-£ 3.3$ million in the period 2003-06

A marked increase in collaboration among scientists, engineers, technologists, and the military was to occur during the Second World War. ${ }^{9}$ From 1939 to the present day, achieving technological improvements in the means of destruction and the maintenance of military superiority became a predominant theme in the majority of industrialized countries. ${ }^{10}$ By developing the atomic bomb, science had demonstrated its role in supporting political power. Others, too, in science, engineering, and technology had shown how valuable they were to achieving military objectives. Their role became embedded within the security matrix, ${ }^{11}$ and it remains so today. By providing the scientific and technical expertise as well as the trained personnel, the universities gained a number of advantages which were effectively denied to many other institutions after the Second World War and particularly during the Cold War. U.K. universities are increasingly seen, particularly with the privatization of the former government research defense establishments, as being vital to identifying and facilitating military objectives. This view was given added support in the U.K. Defence Technology Strategy launched in October 2006.

In tandem with the increasing drive for privatization across government the universities, too, have undergone a series of profound changes in the last thirty years. This includes a period of reduced funding for science, engineering, and technology (SET), especially in the 1980 s and early 1990 s, to produce a highly commercialized 
environment for SET. Locating universities, where the majority of fundamental SET research is undertaken, within a business culture with obvious commercial end-points, creates a number of possible tensions. Entrepreneurial academics often feel reluctant to exchange information that might have commercial importance. ${ }^{12}$ Security-sensitive areas also throw up concerns about aspects of science such as academic freedom and ease of publishing, movement of staff from one country to another, and the kinds of research biases that have been found in the pharmaceutical industry. ${ }^{13}$ Is the provision of research, training, and teaching for military clients conducive to the broader goals of the university?

In the United Kingdom, many departments in the physical sciences have closed or amalgamated in the last twenty years, and those that remain are dominated by significant research funding from many commercial sources, including the military. All these trends not only produce privatized universities but place such institutions in the closed military-industrial complex where decisions are often made without fully transparent and independent expert scrutiny. ${ }^{14}$

Corporate interests are often felt to be best served by secrecy, intellectual property rights monopoly, and the removal of those who appear to be dissidents. ${ }^{15}$ The change in status of the former government defense research laboratories to commercial entities also caused a great deal of concern about intellectual property rights. ${ }^{16}$ These issues have particular salience given that scarcely any SET department in U.K. universities is now free from some form of corporate presence.

Additionally, the creation of science and technology parks together with university-business partnerships are found throughout Britain and other European countries. Such science parks and innovation centers were the vanguard of attempts to exploit research-intensive companies, to transfer new technology developed within universities to the marketplace, and to forge strong links with publicly funded research centers such as those of the research councils and universities. Such parks have had, in their various incarnations, strong links with the military sector, corporate and government, especially in Silicon Valley in California, where Lockheed Martin - a U.S. military corporation - has been heavily involved in software development.

Segal Quince's major study of one such science park, entitled The Cambridge Phenomenon, points out how important was the general growth of national and international advanced electronics and telecommunications companies within and around the city of Cambridge in the U.K., in not only forging strong but often informal links with researchers in the university. ${ }^{17}$ Many of the small to medium technology-intensive firms in the park had military companies as their major clients. Cambridge Consultants, Cambridge Interactive Systems, and Spectronics Micro Systems for instance had as major customers government defense organizations such as the Royal Signals and Radar Establishment or U.K. military corporations.

Increasingly, off-the-shelf commercially available computer technology developed from university-commercial incubators such as science parks finds a place in military uses.
The universities and military $R \& D$

Currently there are five main ways in which MoD funding can reach universities to support R\&D activities with a broad defense objective. ${ }^{18}$ The first is modest direct funding from the MoD, about $£ 220,000$ in fiscal year 2005/06. The second is sub-contracting through the two former government defense research establishments, DSTL and the privatized QinetiQ. The DSTL funds research through contracts in around 60 universities in the United Kingdom, including at the universities of Cranfield, Cambridge, Birmingham, Imperial College London, and Oxford. The third is the Joint Grant Scheme between the research councils and the MoD (and the Department for Trade and Industry when research projects cover the biomedical and physical sciences). The fourth is the Defence Technology Centres (DTCs) and the Interdisciplinary Research Centres (two in nanotechnology and one in advanced computation). DTCs at present receive up to $£ 2$ million each per year from the MoD with matched funding from other consortia members. Currently DTCs support research in electromagnetic remote sensing for target detection and location, data and information fusion (fundamental to the integrated manner in which battlespace is configured), human-factors integration, which addresses optimum ways in which environments can be designed for human activities in conflict, and lastly autonomous systems engineering, the design of a variety of robotic devices for military operations. Around $£ 90$ million has been earmarked for the lifetime of the DTCs from the MoD.

The fifth avenue of funding is through consortia, comprising the MoD, corporations such as BAE Systems and Rolls Royce, and sometimes other government departments. One example is the Defence and Aerospace Research Partnerships (DARPs), which are allied to the Joint Grant Scheme and are part-funded by the MoD, the Engineering and Physical Sciences Research Council (EPSRC), and the former DTI. In 2006, seven DARPs were running across 16 universities and involved research in composites, computation, and aero engineering. Since its inception EPSRC has allocated in excess of $£ 11$ million to the scheme. Funds from the former DTI and corporate sponsorship will add significantly to this figure.

Another form of consortium, called Towers of Excellence, is also being developed. These are joint partnerships, launched in 2002, with industry and government, involving researchers in universities and covering areas such as guided missiles, radar and various sensors, electronic warfare, and computation. Detailed up-to-date information is lacking although they are discussed in the 2006 Defence Technology Strategy.

In addition to their involvement in consortia, military corporations such as BAE Systems, support universities through their more direct involvement in both R\&D and training. Loughborough University, for example, with core funding from the East Midlands Development Agency, collaborates with BAE Systems in the Systems Engineering Innovation Centre (SEIC). This center has supplied systems engineers to BAE (a thousand between July 2004 and the end of 2005). ${ }^{19}$ In the competitive 
world in which BAE operates these trained individuals are lost to nonmilitary sectors. BAE Systems also has a collaborative program with EPSRC ( called FLAVIIR) to the tune of over $£ 6$ million for unmanned airborne vehicles which involves ten U.K. universities including Cranfield, Cambridge, and Imperial College London. Most recently, the Counter Terrorism Science and Technology Centre opened in April 2006. It draws upon academic expertise as well as in-house specialist knowledge from the Ministry of Defence and other government departments. The primary focus of this center is science and technology as tools to safeguard populations against terrorist activities.

In addition, military corporations provide curriculum and staff support in schools and many universities in Britain. Examples include BAE Systems' extensive involvement with various educational programs, including mentoring schemes and their own "university." Boeing Corporation, of the United States, similarly pursues university collaboration, for instance in an advanced manufacturing initiative and a composites program with the University of Sheffield - part of a $£ 45$ million program - and a partnership with the universities of Cranfield, Cambridge, and Sheffield in information technology, aeronautics, and manufacturing.

Clearly in many universities the military sector - both public and private - has a major presence in teaching, training, and research. Universities have thus come to play an important function in the provision of high-technology means for the waging of war and form a key approach to framing security.

The driving of military R\&D deeper into the university research communities with more projects, dedicated staff, and time and opportunity being devoted to security-oriented objectives will not only limit the resources - people, ideas, and expertise - for other needs but will influence the development of science and technology itself. This securitization of science and technology can compromise the knowledge base available for other goals ${ }^{20}$ which may be related to driving conflict. For instance, the development of sensor technologies, which have important functions in environmental and health monitoring in poorer nations, tends to be dominated by military-led R\&D as previously described. Such funding leads to military products, while the nonmilitary uses of sensors, instrumental to improving the health and economic status of communities and making them less prone to conflict, becomes marginalized.

Additionally, an open and disinterested research culture is compromised by commercialization and sensitive security projects. University departments that have been transformed by such involvement and that are small and with their research income dependent on military sources might not feel able to give independent and open advice. Furthermore, the opportunity costs of military R\&D activities on areas such as public health, energy efficiency, and climate change amelioration are simply unknown.

\section{Funding military R\&D}

Revolutions are a commonplace in military circles. Many owe a great deal to input from scientists and engineers, within and outside the universities, and this is particularly true of the so-called Revolution in Military Affairs (RMA). ${ }^{21}$ The United Kingdom and the United States military - corporations, government departments, and pressure groups representing the interests of military manufacturers - have supported and pushed this revolution. High technology is seen by these groups as central to modern security, especially for the C4ISTAR complex (Command, Control, Communications, Computers, Intelligence, Surveillance, Target Acquisition, and Reconnaissance Systems). ${ }^{22}$ Furthermore, many U.K.-U.S. collaborative military activities develop interoperability, the ability of systems, units, or forces of the two nations to work closely together to ensure meeting military objectives of mutual importance. Such interoperability strengthens the U.K. government's commitment to RMA with its supporting R\&D. The International Technology Alliance, for example, is a joint U.K.-U.S. collaboration which seeks areas of mutual interest and concern in the security uses of information and communications technology, a primary focus of $\mathrm{RMA}^{23}$

The RMA has had an indirect effect on military R\&D globally. ${ }^{24}$ The fixed costs of R\&D for the major systems, both platforms and infrastructure (the satellites, strategic air assets as well as the information systems needed for network-centric warfare), continue to grow. Thus there have been powerful drivers for governments, even those of the high-spender category, to look for ways of curbing rising military expenditure and streamlining the procurement process. Such concerns have led to decisions to reform the procurement and research processes to improve efficiency and coordinate those involved in weapons development and acquisition. The first steps were made by George Robertson, U.K. Secretary of Defence in 1997. Successive U.K. governments have decided that such improvements should include the privatization of military research and some aspects of development, and look to the relevant knowledge-base in the U.K. university sector, to augment that from corporate sources. ${ }^{25}$

Prior to 2001, the U.K.'s Defence Evaluation and Research Agency (DERA) and its predecessors the Defence Research Agency (DRA) and the defense research establishments were the major suppliers of research services and military knowhow to the Ministry of Defence. ${ }^{26}$ Thus government had direct access to a highly technical, scientific, and relatively impartial expertise base without the need for extensive use of university expertise. But over the past decade the government has increasingly called upon universities to augment the expertise residing in the offspring of DERA, DSTL and QinetiQ.

Both entities have a special place in framing the U.K.'s security stance and are pivotal players in the military-university consortia in the country, supporting the R\&D central to the RMA. ${ }^{27}$ Such consortia, mentioned earlier, focus on research in sensors, 
communication technology, and computational data handling. For instance, the Electromagnetic Remote Sensing Defence Technology Centre, involving the universities of Birmingham, Edinburgh, Glasgow, Heriot-Watt, Imperial College London, Leeds, Cranfield, St Andrews, Sheffield, Strathclyde, Southampton, and University College London, supports research into sensors in the electromagnetic spectrum. Such devices can improve the detection of military targets - people, vehicles, and buildings - at longer range and in a variety of adverse weather conditions. ${ }^{28}$ Other Defence Technology Centres that involve universities support research and development of autonomous systems engineering (robotic vehicles and their platforms), and data and information handling.

Universities have become indispensable to modern warfare and in maintaining the scientific liaison implicit in various special relationships with the United States. What does all this mean for the universities, the process of technology transfer, and the U.K. defense strategy?

The launch of the Defence Industrial Strategy (DIS), in December 2005, followed by the Defence Technology Strategy (DTS), in October 2006, suggested a number of changes in Britain's military R\&D. One of the key strands in the DTS is to seek, through DSTL, an even closer relationship (in the United Kingdom and further afield) with university expertise in science and technology in order to support military objectives. We have seen already that this will certainly include research in robotic vehicles, satellite systems, and sensor technologies, in addition to newly emerging technologies like nanotechnologies and advanced computational methods. This trend will have the effect of locking-up access to expertise in these areas within universities for nonmilitary uses.

Both DTS and DIS, rather than addressing the broader global security situation and the ways in which the U.K.'s SET community could play a pivotal role, continues the expensive drive for more sophisticated and expensive military weaponry and support platforms. These include the design of complex ships, robotic devices, nuclear submarines, and other expensive means of destruction. ${ }^{29}$ V arious commentators have pointed out that an international security strategy could focus upon many challenges including climate change and resource depletion and the search for clean and sustainable energy sources. ${ }^{30}$ This strategy could harness the expertise residing in U.K. universities in nonoffensive ways.

Conclusions

Universities are very different today than thirty years ago. In Britain, they are now engaged on a sustained and regular basis in a bewildering array of commercial partnerships, including with the military, biotechnology, and electronic sectors Similar trends (not substantiated in this paper) are to be found in the United States. Such partnerships, especially those with the military, change, often in profound ways, how universities function and how staff regard themselves.
A number of far-reaching changes have occurred within the universities and the military procurement process in the past twenty years in the United Kingdom. The military R\&D effort has also undergone many changes that have drawn in the expertise residing in university research communities. This process involves a variety of partnerships with corporate and government entities, which supply funds, research direction, and employment opportunities. Such collaboration raises questions about the role of such universities in teaching, scholarship, and independent thinking, about bias and the availability of university expertise for other, nonmilitary, socially important goals.

The nexus of interacting players, including researchers in the universities, are not only part of the R\&D process supportive of the production of weapons and their support systems, but they help shape the security agenda. The expertise found in U.K universities that is supported by the military sector can effectively lock-up access to nuanced approaches to a variety of global problems, many of which contribute to the drivers of conflict. Military funding thus tends to produce military products and solutions. Additionally, evidence from the last twenty years indicates that technology transfer from military-supported research programs has been disappointing. Bellais and Guichard, in a study of defense innovation and technology transfer, have noted that "current intellectual property laws and practices do not fit technology transfer from the government-funded, secrecy-based defense R\&D to the privately-funded, patent-based civilian industry." ${ }^{\prime 1}$

The RMA has brought about a heavy reliance upon high-technology solutions to security problems, but does such technological warfare actually provide value for money and does it work? Many have raised serious questions about the overwhelming influence of high technology on how warfare and conflict and the conditions for peace are framed. ${ }^{32}$ Has high technology led to the end of a conflict swiftly and effectively? Are there proliferating vulnerabilities in using high technologies in the battlespace? There are many who challenge over-reliance on such means of warfare. ${ }^{33}$

Universities with extensive commercial interests can be compromised in providing access to disinterested views on contentious subjects, a bulwark of openness and democracy. There has in general been little discussion about whether the universities should play increasingly important roles in the R\&D central to the modern conception of warfare.

Openness and free exchange of information is potentially problematic in such sensitive environments, as is the questioning of a markedly weapons-based security stance. Despite a number of studies, it is still unclear what the effects are of commercial partnerships on teaching, intellectual property rights, and research within universities. What is clearly needed is a far-ranging and rigorous debate on the future of the U.K. defense strategy, its dependence upon RMA, and its involvement with universities. It is time that our heavy reliance upon expensive weapons systems with the active involvement of universities be examined closely and contested where necessary. 
Notes

Chris Langley is author of "Soldiers in the Laboratory: Military Involvement in Science and Technology - and Some Alternatives" and of "Scientists or Soldiers? Career Choice, Ethics and the Military" - both available from http://www.sgr.org.uk. $\mathrm{He}$ is principal researcher with Scientists for Global Responsibility, Ingles Manor, Castle Hill Avenue, Folkestone, Kent, CT20 2RD, U.K., and may be reached at ChrisL@sgr.org.uk. Thanks are due to all those who supported the research upon which this article is based, not least the Network for Social Change, Joseph Rowntree Charitable Trust, Martin Ryle Trust, and the supporters of Scientists for Global Responsibility.

\section{SIPRI $(2006,2007)$}

2. DASA (2005); OSI (2005).

\section{DTI (2005)}

\section{Rappert (1999).}

5. See Cantor (1990).

6. Edgerton (2006).

7. Freeman (1997)

8. James (1998).

9. See, e.g., Hartcup (2000).

10. Cozzens (1995); Black (2004).

11. Cozzens (1995).

12. Louis (2001).

13. Cozzens (1995).

14. Nature (2001); Brown (2000).

15. See, e.g., Krimsky (2003).
16. Molas-Gallart and Tang (2006).

17. Segal Quince (1985).

18. These are explored in Langley (2005).

19. Cook (2007).

20. For a discussion of the effect of R\&D activities on the universities, see Noll (1998).

21. The RMA came to international notice during the First Gulf War, but its birth was due to the realizations of Marshall N V Ogarkov, Soviet general staff member. He proposed in 1982 that long-range precision strike weapons such as cruise missiles, when connected to a military telecommunications network, able to gather and distribute a variety of intelligence in three dimensions from the battlefield, could effectively revolutionize the conduct of war. The resultant discussions in both the U.S.and the then Soviet bloc military produced the RMA. See also Blackmore (2005) and Stone (2004).

\section{MoD (2006).}

23. A consortium comprising universities and businesses, including Boeing and Honeywell, and is led by IBM. [ITA] 2007.

24. Mallik (2005); SIPRI (2006, 2007); Byman (2002).

25. Molas-Gallart (2001).

26. James (2005).

27. Langley (2005).

28. Langley (2005).

29. Schofield (2006).

30. Dodds (2005); Abbott (2006); Elworthy (2005); Schofield (2006).

31. Bellais (2006).

32. Blackmore (2005); Stone (2004); Vanderburg (2005). 
33. Dodds (2005); Abbott (2006); Elworthy (2005); Liotta (2005).

\section{References}

Abbott, C., P. Rogers, and J. Sloboda. 2006. "Global Responses to Global Threats: Sustainable Security for the 21 st Century." Briefing Paper. Oxford: Oxford Research Group.

Black, J. 2004. War Since 1945. London: Reaktion Books.

Blackmore, T. 2005. War X: Human Extension in Battlespace. Toronto: University of Toronto Press.

Bellais, R. and R. Guichard. 2006. "Defense Innovation, Technology Transfers and Public Policy." Defense and Peace Economics, Vol. 17, No. 3, pp. 273-286.

Brown, J. R. 2000. "Privatizing the University - The New Tragedy of the Commons." Science, Vol. 290, No. 5497, pp. 1701-1702.

Byman, D. and M.Waxman. 2002. The Dynamics of Coercion: American Foreign Policy and the Limits of Might. Cambridge, UK: Cambridge University Press.

Cantor, G.N., J.R.R. Christie, M.J.S. Hodge, and R.C. Olby. 1990. Companion to the History of Modern Science. London: Routledge.

Cook, N. 2007. “Capability Culture.” Jane's Defence Weekly, 31 January 2007, pp. 22-29.

Cozzens S.E. and E.J. Woodhouse. 1995. "Science, Government and the Politics of Knowledge," pp. 533-553, in S. Jasanoff, G.E. Markle, J.C. Peterson, and T Pinch, eds. Handbook of Science and Technology Studies. London: Sage Publications.

[DASA] Defence Analytical Services Agency. 2006. http://www.dasa.mod.U.K./ natstats/U.K.ds/2005/U.K.ds.html [accessed 24 August 2007].

[DTI] Department of Trade and Industry. 2005. "The 2005 R\&D Scoreboard." London: Department of Trade and Industry.

Dodds, F. and T. Pippard, eds. 2005. Human and Environmental Security: An Agenda for Change. London: Earthscan Books.

Dunne, J.P. 1995. "The Defense Industrial Base," pp. 400-430 in K. Hartley and T. Sandler, eds. Handbook of Defense Economics, vol.1. Amsterdam: Elsevier.

Edgerton, D. 2006. Warfare State - Britain, 1920-1970. Cambridge, UK: Cambridge University Press.

Elworthy, S. and G. Rifkind. 2005. Hearts and Minds. London: Demos.

Freeman, C. and L. Soete. 1997. The Economics of Industrial Innovation. 3rd ed. London: Pinter.

Hartcup, G. 2000. The Effect of Science on the Second World War. London: Macmillan and St. Martin's Press, London.

[ITA] International Technology Alliance Programme on Network and Information Sciences. 2007. "A Consortium Comprising Universities and Businesses, including Boeing and Honeywell, and is Led by IBM." http://www.usukita.org [accessed 16 April 2007].

James, A.D. and P. Gummett. 1998. "Defence," pp. 269-296 in P. Cunningham, ed Science and Technology in the United Kingdom. 2nd ed. London: Catermill.

James, A.D., D. Cox, and J. Rigby. 2005. "Testing the Boundaries of Public Private Partnerships: the Privatisation of the U.K. Defence Evaluation and Research Agency." Science and Public Policy, Vol. 32, pp. 155-161.

Krimsky, S. 2003. Science in the Private Interest. Lanham, MD: Rowman \& Littlefield.

Langley, C. 2005. "Soldiers in the Laboratory: Military Involvement in Science and Technology - and Some Alternatives." Folkestone: Scientists for Global Responsibility. http://www.sgr.org.uk.

Liotta, P.H. 2005. "Through the Looking Glass: Creeping Vulnerabilities and the Reordering of Security.” Security Dialogue, Vol. 36, No. 1, pp. 49-70.

Louis, K.S., L.M. Jones, M.S.Anderson, et al. 2001. "Entrepreneurship, Secrecy and Productivity: A Comparison of Clinical and Non-clinical Faculty." Journal of Technology Transfer, Vol. 26, pp. 233-245.

Mallik, A. 2004. Technology and Security in the 21st century: A Demand-side Perspective. Oxford, New York: Oxford University Press.

[MoD] Ministry of Defence. 2006. Research Acquisition Yearbook 2006. London: Ministry of Defence.

Molas-Gallart, J. 2001. "Government Defence Research Establishments: the Uncertain Outcome of Institutional Change." Defence and Peace Economics, Vol. 12, No. 5, pp. 417-437.

Molas-Gallart, J. and P. Tang. 2006. "Ownership Matters: Intellectual Property, Privatization and Innovation.” Research Policy, Vol.35, No. 2, pp. 200-212.

[Nature] Anonymous. 2001. "Is the University-industry Complex out of Control?" Nature, Vol. 409, No. 119, p. 19

Noll, R.R., ed. 1998. Challenges to Research Universities. Washington, DC: The Brookings Institution Press.

O'Hanlon, M. 2000. Technological Change and the Future of Warfare. Washington, DC: The Brookings Institution Press.

[OSI] Office of Science and Innovation [now Department for Innovation, Universities and Skills]. 2007. http://www.dti.gov.U.K./science/.

Rappert, B., A. Webster, D. Charles. 1999. "Making Sense of Diversity and Reluctance: Academic-Industrial Relations and Intellectual Property." Research Policy, Vol. 28, No. 8, pp. 873-889.

Schofield, S. 2006. "The U.K. Defence Industrial Strategy and Alternative Approaches." BASIC Paper 50. London: BASIC. http://www.basicint.org/pubs/ Papers/BP.pdf [accessed 8 September 2006].

Segal Quince. 1985. “The Cambridge Phenomena.” Cambridge, UK: Segal Quince \& Partners.

[SIPRI] The Stockholm International Peace Research Institute. 2006. The Stockholm 
International Peace Research Yearbook 2005. Oxford: Oxford University Press. [SIPRI] The Stockholm International Peace Research Institute. 2007. The Stockholm International Peace Research Yearbook 2006. Oxford: Oxford University Press. Stone, J. 2004. "Politics, Technology and the Revolution in Military Affairs." Journal of Strategic Studies, Vol. 27, No. 3, pp. 408-427.

Vanderburg, W.H. 2005. Living in the Labyrinth of Technology. Toronto: University of Toronto Press. 